Revue Française de Civilisation Britannique en Grande-Bretagne, 1990-2000

\title{
Kathleen BURK (ed), The British Isles Since 1945
}

Short Oxford History of the British Isles, Oxford: OUP, 2003

Jean-Paul Révauger

\section{(2) OpenEdition}

\section{Journals}

Édition électronique

URL : http://journals.openedition.org/rfcb/3192

DOI : $10.4000 /$ rfcb.3192

ISSN : 2429-4373

Éditeur

CRECIB - Centre de recherche et d'études en civilisation britannique

Édition imprimée

Date de publication : 1 avril 2003

ISBN : 2-911580-16-8

ISSN : 0248-9015

Référence électronique

Jean-Paul Révauger, «Kathleen BURK (ed), The British Isles Since 1945 », Revue Française de Civilisation Britannique [En ligne], XII-2 | 2003, mis en ligne le 01 avril 2003, consulté le 25 septembre 2020. URL: http://journals.openedition.org/rfcb/3192 ; DOI : https://doi.org/10.4000/rfcb.3192

Ce document a été généré automatiquement le 25 septembre 2020.

\section{cc) (D) $\odot$}

Revue française de civilisation britannique est mis à disposition selon les termes de la licence Creative Commons Attribution - Pas d'Utilisation Commerciale - Pas de Modification 4.0 International. 


\section{Kathleen BURK (ed), The British Isles Since 1945}

Short Oxford History of the British Isles, Oxford: OUP, 2003

Jean-Paul Révauger

\section{RÉFÉRENCE}

Kathleen BURK (ed), The British Isles Since 1945, Short Oxford History of the British Isles, Oxford: OUP, 2003, 275 p. ISBN (Pbk) 0199248389.

1 Cet ouvrage de grande qualité semble tout à fait adapté aux besoins des étudiants de licence et de "master ». En effet, il concilie les besoins d'un traitement chronologique, présent dans chaque chapitre thématique, et ceux d'une spécialisation. Il échappe donc aux travers habituels des livres d'histoire qui privilégient parfois la chronologie en traitant confusément d'économie, de culture, de politique intérieure à propos de chaque période ou qui, au contraire, approfondissent l'étude des évolutions dans tel ou tel domaine en perdant de vue la dynamique du changement global. La politique intérieure, l'économie, les questions sociales, la culture, la politique étrangère et même la question irlandaise font l'objet de chapitres distincts, qui tous sont organisés de façon chronologique rigoureuse. L'ouvrage, bien que collectif, évite les travers habituels du genre, car les chapitres sont rédigés par des spécialistes éminents dans chaque domaine, et l'ensemble a été fermement coordonné par Kathleen Burk, spécialiste d'histoire diplomatique à University College, London. La très forte structuration du livre le rend non seulement accessible, mais plaisant. L'équilibre interne entre les différentes thématiques est particulièrement remarquable. Il est rare de trouver, dans un même ouvrage, des chapitres traitant de la "science lugubre ", de l'histoire politique, et des évolutions en matière culturelle. Bien des éditeurs font souvent le choix d'un partage des tâches et du "marché » entre différents ouvrages, dont les maquettes tristement officielles ou au design post-moderne soulignent l'identité. On ne peut que se réjouir de voir la démarche plurielle de la «nouvelle 
histoire » et de la « civilisation » adoptée et légitimée. L'économie, l'histoire culturelle, l'histoire sociale sont tout aussi importantes que l'histoire institutionnelle. Le lecteur européen s'interrogera seulement peut-être sur l'opportunité d'inclure un chapitre sur l'histoire de l'Irlande, et sur la pertinence historique de la notion de British Isles aujourd'hui, dans la mesure où la nation irlandaise jouit en Europe d'une dynamique propre et reconnue. Peut-être ce choix éditorial a-t-il été fait dans la perspective du marché américain, qui a une vision plus lointaine de ces choses.

2 Néanmoins, ses qualités de clarté et de communication ne font pas de ce livre un simple ouvrage pédagogique de nature descriptive. Les analyses sont organisées autour de problématiques pertinentes dans chaque champ considéré, et présentées de façon dynamique, comme des démonstrations. Pour autant, les auteurs ne s'adressent pas seulement à des spécialistes de leur discipline. On ne trouve pas trace ici de cette irritante habitude du clin d'œil aux initiés, et le lecteur ne ressent pas le besoin de faire semblant de connaître d'obscurs groupes pop des années soixante ou le chiffre de la production automobile en 1974, de crainte de passer pour un ignorant. Il s'agit bien d'idées, et non d'érudition. L'historien, disait en substance Leroy Ladurie, est soit un parachutiste, qui a une vision globale des choses, mais ne connait pas les détails, soit un chercheur de champignons, qui a le nez dans la mousse mais n'a aucune idée de l'étendue de la forêt. Nous sommes en présence ici d'historiens compétents, qui ont une vision globale, mais qui mettent des données factuelles nombreuses et maîtrisées au service de leur démonstration. Ce livre peut donc nous apporter à la fois des connaissances et des méthodes.

3 La lecture de ce livre permet de prendre toute la mesure de l'importance des changements économiques, sociaux, politiques et identitaires intervenus avec la fin de l'ère industrielle. L'analyse du thème du déclin, cher aux thatchériens d'antan, permet de rappeler que la Grande-Bretagne reste un des pays les plus riches et les plus influents du monde, chose que l'ampleur des inégalités fait trop souvent oublier depuis vingt ans de ce côté-ci de la Manche (p.87). Dans les années 1990, le retour à un degré d'inégalité comparable à celui des années 1880 (p.124), la domination totale de la fraction de la classe moyenne associée au secteur privé sur celle qui était liée au secteur public et sur la classe ouvrière résultent de changements aussi significatifs que la révolution industrielle du début du XIX ${ }^{e}$ siècle (p.114). Les grandes problématiques des Cultural Studies - américanisation, démocratisation de la culture, ambiguïté de la culture commerciale de masse - sont évoquées avec bonheur.

On restera tout au plus sceptique devant certaines assertions, par exemple celle qui consiste à présenter le passéisme et l'opposition à la culture industrielle comme aussi virulents en France qu'en Grande-Bretagne (p.87). Il reste en effet à démontrer que la nostalgie est aussi influente dans la France positiviste et globalement républicaine qu'outre-Manche. On ne peut tenir rigueur à des historiens aussi sérieux que les auteurs de cet ouvrage de ne pas entrer dans des détails, et de ne pas étayer toutes leurs assertions par des références. On croit donc Jose Harris sur parole lorsqu'elle évoque les changements dans les mentalités et qu'elle explique le retour des femmes vers leur foyer après 1945 par la nécessité de consacrer beaucoup de temps aux courses et à la gestion du foyer en ces temps de restrictions et de rationnement (p.98).

5 Ce travail de synthèse de grande ampleur, utile et clair, à la fois chronologique, thématique et problématisé peut utilement figurer dans les bibliographies, et donnera du plaisir à ses lecteurs. 


\section{AUTEURS}

JEAN-PAUL RÉVAUGER

Université Michel de Montaigne Bordeaux 3 